\title{
Judgment of temporal duration of area as a function of stimulus configuration
}

\author{
SUCHOON S. MO and VALERIE A. MICHALSKI \\ University of Detroit, Detroit, Mich. 48221
}

When stimuli consisted of two circles, one smaller than the other, and a compound of these two, the larger circle was judged to be longer in duration than the smaller circle. This tendency was accentuated if the presentation of the larger circle was less frequent. The compound stimulus was not generally judged to be longer in duration than the large circle.

A previous study (Mo, 1971) indicated that if eachstimulus consists of a number of dots, the judgment of duration is a monotonically increasing function of the numerosity of such dots. The possibility that this monotonicity results from attentional mediation and not from the mechanism of subjective time itself was ruled out, primarily because such attentional factors as a sudden change of numerosity or duration accentuated the tendency for overestimation of duration only with respect to an increase in numerosity, not with respect to a decrease in numerosity. But the question of whether attention was an integral part of judgment of duration was not raised, because the precise temporal nature of attention was not specified. In order to deal with this question, the following assumption may be made to specify the relationship between the temporal aspect of attention and judged duration: time required to initiate and maintain a given level of attention is additive to, and an integral part of, judged temporal duration.

Let $S 1$ and $S 2$ be two circles, with $\mathbf{S 1}$ smaller than $\mathbf{S 2}$, and let $\mathbf{S 1}+\mathbf{S 2}$ be a compound stimulus consisting of these two circles. The prediction in accordance with the original assumption would be that $\mathrm{S} 1+\mathrm{S} 2$ should not be judged to be shorter in duration than $\$ 2$, because neither the area nor the complexity of $\mathrm{S} 1+\mathrm{S} 2$ is less than that of S2. Any evidence to the contrary would render such an assumption difficult to sustain.

\section{EXPERIMENT 1}

Subjects

Sixty undergraduate volunteers were recruited from introductory psychology courses.

Apparatus

S1 was a circle of $9 \mathrm{~mm}$ diam; $\mathrm{S} 2$ was a circle of $30 \mathrm{~mm}$ diam. The compound $\mathrm{S} 1+\mathrm{S} 2$ was formed by a concentric combination of $\mathrm{S} 1$ and $\mathrm{S} 2$. These circles were drawn in dark ink on white cardboard. The presentation of each stimulus was conducted by means of a Lafayette Model U-1 tachistoscope.

\section{Procedure}

The task called for recognition of two durations: 450 and $510 \mathrm{msec}$. Each $\mathrm{S}$ was presented with one of the three stimuli in each trial, and his task was to identify its duration by saying either "short" or "long." There were, altogether, 60 trials for each $S$, and the average intertrial inverval, as estimated from the total running time, was about 5 sec.

There were four groups, G1, G2, G3, G4, of $15 \mathrm{Ss}$ each, each group being differentiated from others on the basis of distribution of stimuli. The number of trials for each stimulus in the order of $\mathrm{S1}, \mathrm{S2}$, and $\mathrm{S1}+\mathrm{S2}$ were: 20,20 , and 20 for $\mathrm{G} 1 ; 40,10$, and 10 for $G 2 ; 10,40$, and 10 for $G 3$; and 10,10 , and 40 for G4. The relative frequencies of the short and long durations were both .50 . In order to insure a constant level of light adaptation, Ss were not allowed to detach their faces from the eyepiece throughout the session.

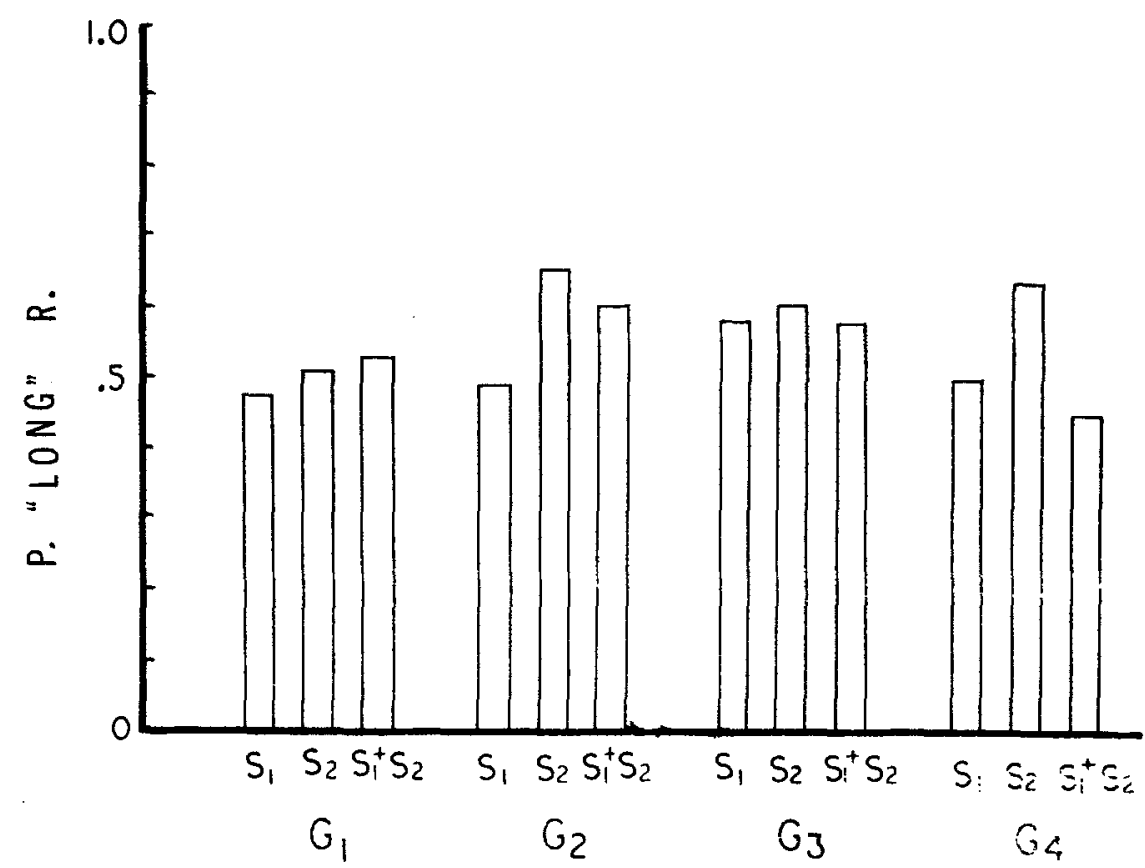

Fig. 1. The probabilities of "long" responses with respect to each stimulus.
The probults and Discussion "long" responses for each stimulus are shown in Fig. 1. It can be seen that, except for G1, the probabilities of "long" responses for $\mathbf{S 1}+\mathbf{S 2}$ are less than for S2. The numbers of Ss who judged $\mathrm{S} 1+\mathrm{S} 2$ to be shorter in duration than S2 were, in the order of G1, G2, G3, and G4: 5, 9, 9, and 12. The prediction that $\mathbf{S} 1+\mathbf{S} 2$ is judged to be longer in duration than $\mathbf{S 2}$ is generally contradicted, and this contradiction becomes more pronounced as the frequency of presentation of $\mathbf{S 1}+\mathbf{S 2}$ is increased, as in G4. It is also observed that $\mathbf{S} 2$ is generally judged to be longer in duration than $S 1$, and this tendency is more pronounced in $\mathbf{G 2}$ and G4. The results of a Mann-Whitney $U$ test indicated that this tendency is statistically significant for G2 $(p<.02)$ and G4 $(p<.05)$. It is noted that the exaggeration of this tendency in G2 and G4 is primarily due to the increased overestimation of the duration of S2. Therefore, the possible factor of cue selection or selective attention may be taken into consideration. If $\mathbf{S} 1$ is selected from $\mathrm{S} 1+\mathrm{S} 2$ and if judgment of duration proceeds subsequently, the frequencies of presentation of $\mathrm{S} 1$ and $\mathrm{S} 2$ would be functionally 50 and 10 for both G2 and G4. Since infrequent presentation of a stimulus accentuates the existing tendency of temporal judgment associated with that stimulus (Mo, 1971), this infrequent presentation of S2 may be regarded as a factor which accentuates the tendency for overestimation associated with S2. As 


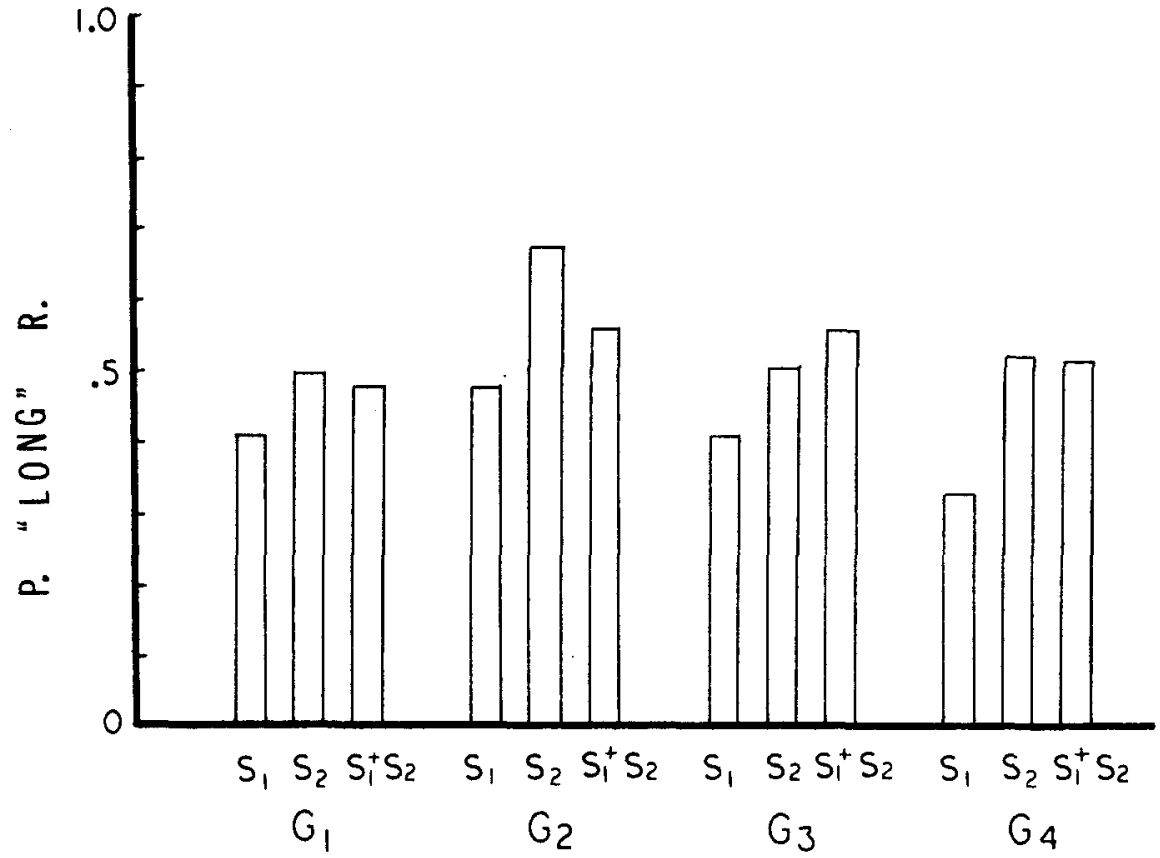

Fig. 2. The probabilities of "long" responses with respect to each stimulus.

to the probabilities of correct recognition of durations, they were, in the order of S1, S2, and S1 + S2:.64, .55 , and .64 for $\mathrm{G1} ; .70, .67$, and .69 for $\mathrm{G} 2 ; .69, .66$, and .70 for $\mathrm{G} 3$; and $.67, .66$, and .67 for $\mathrm{G} 4$.

Although it was generally shown that $S 1+S 2$ is not judged to be longer in duration than $\mathrm{S2}$, the question may be raised as to whether time required for cue selection or selective attention may be an integral part of judged duration. Since the process of selective attention ought to be best established in G4, having the greatest frequency of presentation of $\mathrm{S} 1+\mathrm{S} 2, \mathrm{~S} 1+\mathrm{S} 2$ should be judged to be longer in duration than $S 1$. The results are contrary to this argument, and time required to initiate and complete selective attention cannot be regarded as an integral part of judged duration.

Perhaps this experiment, by using concentric circles, is too biased in favor of selective attention to $\mathrm{S} 1$. Whether $\mathrm{S} 1+\mathrm{S} 2$ is judged to be longer than S2 in the case of nonconcentric circles is yet to be demonstrated.

\section{EXPERIMENT 2} Method

The number of Ss, group assignment, and procedure were the same as in Experiment 1, except that $\mathrm{S} 1$ + S2 consisted of a nonconcentric combination of $\mathrm{S} 1$ and $\mathrm{S} 2$, which were $25 \mathrm{~mm}$ apart horizontally from origin to origin.

\section{Results and Discussion}

The probabilities of "long" responses for each stimulus are shown in Fig. 2. The results of the Mann-Whitney $U$ test indicated that the tendency for $S 2$ to be judged to be longer in duration than S1 was statistically significant for G2 $(\mathrm{p}<.002)$ and G4 $(\mathrm{p}<.02)$. The number of Ss who judged S2 to be longer in duration than $\mathrm{S} 1$ were, in the order of G1 to G4: 11, 14, 11, and 12 .

As to $\mathbf{S 1}+\mathbf{S 2}$, except for $\mathrm{G} 3$, it was not judged to be longer in duration than S2. However, the results of the Mann-Whitney U test showed that the difference in judgment between $\mathrm{S} 1+\mathrm{S} 2$ and $\mathrm{S} 2$ did not reach the $5 \%$ level of significance except for G2. It is reasonable to conclude that $\mathrm{S} 1+\mathrm{S} 2$ is not generally judged to be longer in duration than $\mathrm{S} 2$; the overall tendency appears to be the opposite. The probabilities of correct recognition of durations with respect to $\mathrm{S} 1, \mathrm{~S} 2$, and
$\mathrm{S} 1+\mathrm{S} 2$ were $: 60, .59$, and .60 for $\mathrm{G} 1$ $.71, .62$, and .69 for $\mathrm{G} 2 ; .65, .72$, and .69 for $\mathrm{G} 3$; and $.61, .73$, and .65 for G4

\section{GENERAL DISCUSSION}

The original assumption that time required to initiate and maintain attention is an integral part of judged duration is contradicted by the findings of this study. As long as attention is conceptualized spatially in terms of selectivity, generality, or otherwise, it cannot be regarded as an integral part of the mechanism of subjective time. Although the tendency to judge $\mathrm{S} 1+\mathrm{S} 2$ to be shorter in duration than $\mathrm{S1}$ is less in the case of nonconcentric circles than concentric circles, in neither case is $\mathrm{S} 1+\mathrm{S} 2$ generally judged to be longer in duration than S1 or S2. Therefore, attention, even if a selective one, cannot be an integral part of judged duration.

It is known that judgment of duration is a monotonically increasing function of such nontemporal stimulus attributes as intensity, extensity, complexity, and background context (Fraisse, 1963, p. 134). The observed tendency for $\mathrm{S} 2$ to be judged longer in duration than $\mathrm{S} 1$ is in accordance with such monotonicity. However, the argument that this monotonicity comes about through attentional mediation must explain why the compound stimulus is not always judged to be longer in duration than its components.

Perhaps too many spatial, and not too few temporal, references have been applied to the concept of attention. As far as the problems of temporal judgment are concerned, it may be better to define attention temporally. In this sense, the question of whether attention is a part of the mechanism of subjective time may be not too good a question. Since temporality is common to different sense modalities, it may be more practical to ask whether the mechanism of subjective time is an integral part of attention.

\section{REFERENCES}

FRAISSE, P. The psychology of time. New York: Harper \& Row, 1963.

MO, S. S. Judgment of temporal duration as a function of numerosity. Psychonomic Science, 1971, 24, 71-72. 